\title{
The Distribution, Metabolism, and Excretion of Hydrazine in Rat and Mouse
}

\author{
Thomas Dambrauskas and Herbert H. Cornish \\ Department of Industrial Health and Institute of Industrial Health, \\ School of Public Health, University of Michigan, \\ Ann Arbor, Michigan \\ Received July 30, 190.3
}

Prior to World War II, hydrazine was primarily of scientific interest without wide application for practical purposes. IIowever, during World War II the Germans dcveloped techniques for the production of hydrazine hydrate on a tonnage scale for use as rocket and jet fuel, and since then hydrazine and its derivatives have attracted increasing attention from chemists, manufacturers, and the military. Presently, the application of hydrazine and its derivatives include uses in research laboratories, production of fuel, explosives, photographic chemicals, chemiluminescent materials, insecticides, plastics, rubber chemicals, textile treating agents, dyes, pharmaceuticals, antioxidant preservatives, metallization of glass, solder flux for aluminum and magnesium alloys, and a variety of military applications.

To a limited extent the toxicity of hydrazine has been studied and its toxic properties have been determined. However, the complete metabolic aspects of this compound are not defined. This paper presents a study of the tissue distribution, metabolic pattern, and excretion of hydrazine in the mouse and rat.

\section{METHODS}

\section{Animals}

Male albino Swiss ICR mice, 22-30 g, and male albino rats of the Sprague-Dawley (Holtzman) strain, 330-450 g, were used throughout the study. Water was provided, but food was not available to the rats during the period (maximum, 20 hours) between administration of hydrazine and sacrifice. Rockland chow ration, ground and mixed with water, was available ad libitum to the mice during these studies.

\section{Dosing Procedure}

Reagent grade hydrazine, Eastman Kodak, 902, was used throughout the study. Rats were injected subcutaneously, mice subcutaneously and intravenously. Hydrazine was diluted with double-distilled water before administration: 1:100 for rats and $1: 250$ for mice.

The accuracy of the syringe used for injection was checked by determining the hydrazine content of measured amounts of solution. Three samples of diluted hydrazine $(1: 100)$, containing $1.72 \mathrm{mg}, 1.40 \mathrm{mg}$, and $1.00 \mathrm{mg}$ of hydrazine measured with the same syringe were analyzed as described under Analytical Methods. The average 
amount of measured hydrazine was found to be $102.5 \pm 2.0 \%$ of the calculated amount.

After the administration of hydrazine, the animals were placed in Pyrex glass funnels with the stems extending into graduated cylinders containing $2.5 \% p$-dimethylaminobenzaldehyde in methanol. To avoid any loss of hydrazine in urine, small pieces of glass wool, impregnated with $p$-dimethylaminobenzaldehyde solution, were placed into the stems at the bases of the funnels. The inside walls of the graduated cylinders and the inside of the funnels (starting about 2 inches above the stem) were rinsed with the same solution. The funnels were flushed periodically with $p$-dimethylaminobenzaldehyde solution to assure immediate contact of the aldehyde with the urine.

\section{Analytical Methods}

A modified spectrophotometric method (Dambrauskas and Cornish, 1962) was used for the quantitative determination of hydrazine in the biological material.

Mice. After injection with a determined amount of hydrazine, the mice were placed in special Pyrex glass funnels equipped with a feeding device and allowed to remain for a predetermined period of time; the urine was collected as described above. After the appropriate period of time, each mouse was homogenized for a few seconds in the glass container of a Waring blendor containing ca $80 \mathrm{ml}$ of $2.5 \%$-dimethylaminobenzaldehyde in methanol. The homogenate was then transferred to the $250-\mathrm{ml}$ glass container of a Virtis no. 45 macro homogenizer, the glass container of the Waring blendor was washed with $p$-dimethylaminobenzaldehyde solution, and the washing was added to the homogenate. The glass container of the Virtis homogenizer was filled to about three-fourths capacity with $p$-dimethylaminobenzaldehyde solution (total ca. $160 \mathrm{ml}$ ) and placed in a cooling cup containing ice; the carcass was homogenized for 10 minutes.

The homogenate was then allowed to stand for 4 hours at room temperature, filtered through a medium sintered-glass Büchner funnel, and washed with $150-200 \mathrm{ml}$ of $2.5 \% p$-dimethylaminobenzaldehyde solution (small amounts of azine are soluble in large volumes of $p$-dimethylaminobenzaldehyde solution and do not crystallize for days or weeks).

Usually $150-200 \mathrm{ml}$ of $p$-dimethylaminobenzaldehyde solution is a sufficient amount to wash all azine from a homogenized carcass. The completeness of azine washing was checked by collecting a few drops of filtrate from the tip of the funnel and adding a drop of acetic acid. The development of visible orange-yellow color indicates that washing is insufficient and should be continued until the collected filtrate is color free after addition of acetic acid.

The filtrate was diluted $1: 15$ of the mouse body weight with $p$-dimethylaminobenzaldehyde solution. An aliquot of 5-15 ml (depending upon the amount of hydrazine administered and the length of the period after which a mouse was sacrificed) was diluted to $50 \mathrm{ml}$ with glacial acetic acid, and the absorbance was measured at $480 \mathrm{mu}$ on a Beckman DU spectrophotometer.

The cumulative urinary excretion was collected in a $25-\mathrm{ml}$ graduated cylinder initially containing $5 \mathrm{ml}$ of $2.5 \%$-dimethylaminobenzaldehyde in methanol. After the collection of urine was completed, an additional amount of $p$-dimethylaminobenzaldehyde solution was added to bring the total volume to $20 \mathrm{ml}$ and the mixture was 
allowed to stand for 4 additional hours. The solution was then transferred to a $100-\mathrm{ml}$ volumetric flask and diluted to the mark with glacial acetic acid. A 5-ml aliquot was diluted further to $50 \mathrm{ml}$ with glacial acetic acid and the absorbance measured at $480 \mathrm{~m} \mu$.

The control mice were treated in a similar manner and Beckman readings were substracted from the test mice readings. The amount of hydrazine present in the mouse carcass and urine was determined from a standard curve prepared by using pure $p$-dimethylaminobenzaldazine as a standard, representing proportional amounts of hydrazine.

To identify $p$-dimethylaminobenzaldazine formed in the mouse carcass, a mouse was injected subcutaneously with $100 \mathrm{mg}$ of hydrazine per kilogram and 1 hour later was processed as described above. Crystals of $p$-dimethylaminobenzaldazine were isolated from the carcass filtrate. The melting point was $266^{\circ} \mathrm{C}$. A pure $p$-dimethylaminobenzaldazine was synthesized and the melting point found to be $265^{\circ} \mathrm{C}$. Infrared spectra of the two compounds, using $\mathrm{KBr}$ pellets, were run on a Perkin-Elmer 221 infrared spectrophotometer on the same chart, and identical spectra were obtained (Fig. 1).

To check the accuracy of the method, four mice at different times were injected with $60 \mathrm{mg} / \mathrm{kg}$ of hydrazine and analyzed immediately according to the abovedescribed procedure. The average amount of hydrazine recovered was found to be $101.1 \pm 1.4 \%$ of the calculated amount.

As previously mentioned, the homogenate of the mouse (in p-dimethylaminobenzaldehyde solution) was allowed to stand for 4 hours in order to extract all available hydrazine from the tissue and give sufficient time for aldazine formation. To be certain that all hydrazine was extracted from the tissue during the 4-hour period, mice were injected with $60 \mathrm{mg}$ of hydrazine per kilogram and homogenized; the homogenate was allowed to stand for 20 hours. The resulting recovery of hydrazine was similar to the average for those homogenates allowed to stand for only 4 hours.

Rats. Rats were injected and urine was collected as described for mice. The animals were sacrificed by decapitation; blood was collected in a $25-\mathrm{ml}$ graduated cylinder containing $15 \mathrm{ml}$ of $p$-dimethylaminobenzaldehyde solution. Urine remaining in the bladder was removed with a syringe and added to the urine collected previously.

The organs were removed rapidly and placed in separate glass homogenizers containing an appropriate amount (1:5) of $p$-dimethylaminobenzaldehyde solution. After all organs were removed, they were homogenized and allowed to stand for 4 hours at room temperature. A $10-\mathrm{ml}$ aliquot of liver homogenate, a $10-\mathrm{ml}$ aliquot of intestinal tract homogenate, and the whole homogenates of the rest of organs, including the blood, were each filtered through sintered-glass UF Büchner funnels and washed with $15 \mathrm{ml}$ of $2.5 \%$-dimethylaminobenzaldehyde in methanol. The filtrates were diluted appropriately with $p$-dimethylaminobenzaldehyde and glacial acetic acid and the concentration of hydrazine was determined as previously described.

To confirm the presence of hydrazine in rat urine, crystals of $p$-dimethylaminobenzaldazine were isolated from the urine after rats were injected with hydrazine. The melting point was checked and found to be $266^{\circ} \mathrm{C}$. The infrared spectrum was compared with synthesized p-dimethylaminobenzaldazine on the same chart; the patterns were found to be identical (Fig. 2). 


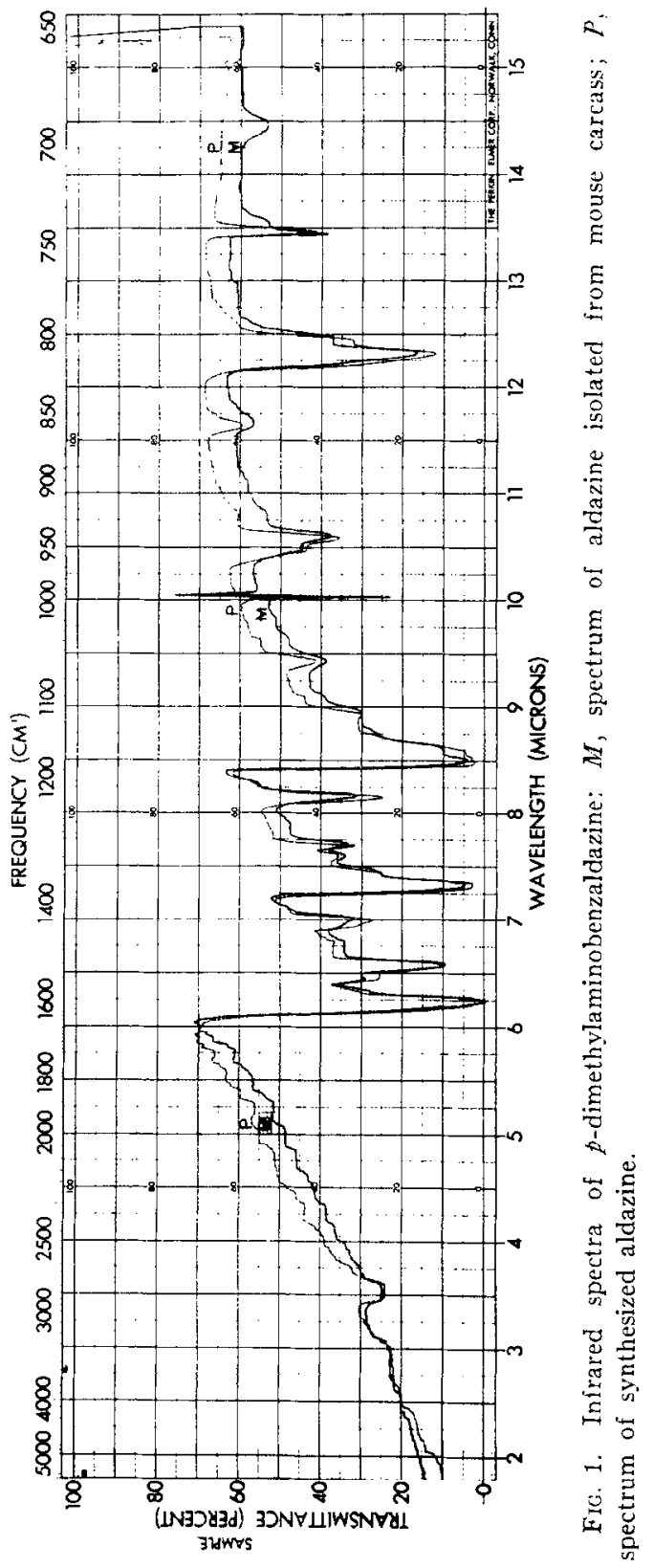




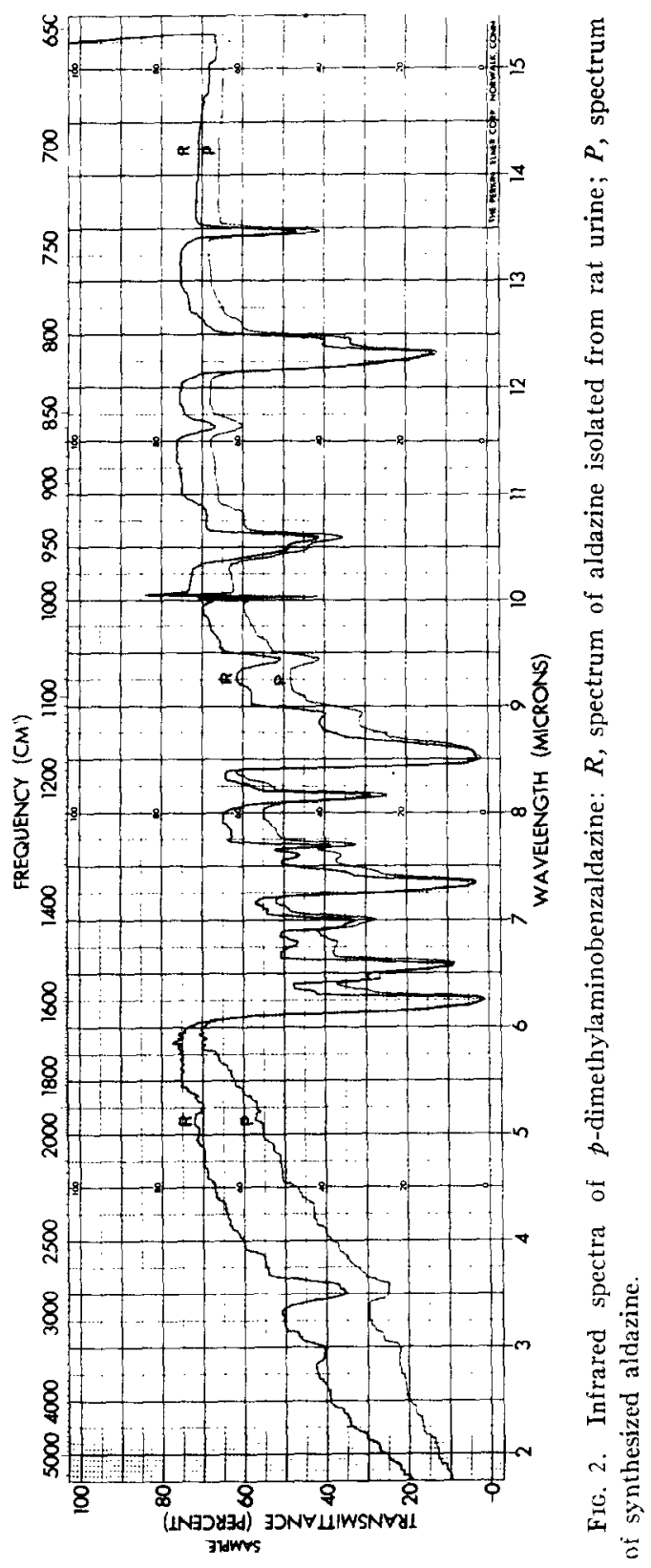


The amount of hydrazine in rat organs is too small to isolate $p$-dimethylaminobenzaldazine crystals from the filtrates. A Conway diffusion procedure was utilized to identify hydrazine in tissues.

Rats were injected subcutaneously with $100 \mathrm{mg}$ of hydrazine per kilogram and urine was collected during the subsequent 1-hour period.

A mixture of $5 \%$-dimethylaminobenzaldehyde in water and glacial acetic acid $(1 ; 1)$ was prepared and placed in the inner chambers of Conway diffusion cells.

One hour post-injection, the rats were sacrificed by decapitation, blood was collected and homogenized in $15 \mathrm{ml}$ of methanol, and the liver was removed and homogenized in methanol, 1:5. Aliquots of the homogenates were placed in the outer chambers of Conway diffusion cells. One milliliter of urine was also placed in the outer chamber of a Conway diffusion cell, and $1 \mathrm{ml}$ of methanol was added. The dishes were sealed with a lubricated glass plate and warmed to $37^{\circ} \mathrm{C}$. All samples developed a light orange color characteristic of $p$-dimethylaminobenzaldazine. A longer period of time ( $2-3$ hours) is required to develop the color when the samples are not warmed. No color developed in the control samples prepared the same way.

\section{RESULTS}

\section{The Fate of Hydrazine in the Mouse}

Mice were injected with $40,60,80,90$, and $100 \mathrm{mg} / \mathrm{kg}$ in single doses and sacrificed after $0.5-48$ hours. Doses of 40 and $80 \mathrm{mg} / \mathrm{kg}$ were injected in two portions, the second portion being injected 0.5 hour after the first. Doses of $90 \mathrm{mg} / \mathrm{kg}$ were also injected in two portions: $60 \mathrm{mg} / \mathrm{kg}$, plus $30 \mathrm{mg} / \mathrm{kg}$ after 0.5 hour, and $60 \mathrm{mg} / \mathrm{kg}$, plus $30 \mathrm{mg} / \mathrm{kg}$ after 20 hours. The animals were sacrificed 0.5 hour after second dose.

The total recovery of hydrazine was determined from the cumulative urinary excretion and from the carcass analysis. The difference between the amount of hydrazine administered to the mouse and that recovered from the urine and carcass was considered to represent metabolized hydrazine (Table 1).

From the data presented in Table 1, it can be seen that the greatest amount of hydrazine is metabolized within half an hour $(B, H, L, N, R)$ and the maximum amount is metabolized within 1-2 hours ( $D, I, M, O, S$ ). Metabolism takes place more rapidly when hydrazine is injected intravenously (Table 1, A,G). After 2 hours, the amount of metabolized hydrazine remains constant $(50-60 \%)$ throughout the remainder of the 48-hour period.

Only a small amount of hydrazine is excreted with the urine during the first half hour after injection regardless of the dose level. Starting one-half to 2 hours after injection, total urinary excretion gradually increases and recovery from the carcass decreases. Thirty-one to $37 \%$ of $40-$ and $60-\mathrm{mg} / \mathrm{kg}$ doses of hydrazine are excreted in the urine within 20 hours and 47 to $48 \%$ within 48 hours. Only $0.3 \%$ of the 40 $\mathrm{mg} / \mathrm{kg}$ dose and $1.4 \%$ of the $60 \mathrm{mg} / \mathrm{kg}$ dose was found in the carcass after the 48 -hour period. No traces of hydrazine were found in the carcass after 72 hours.

Figure 3 illustrates the general pattern of the fate of hydrazine in the mouse after the injection of $60 \mathrm{mg} / \mathrm{kg}$. A nearly identical pattern is obtained after a $40-\mathrm{mg} / \mathrm{kg}$ dose (Fig. 4). These patterns illustrate clearly the rapid drop in total recoverable hydrazine (metabolized) during the first half hour after injection. After this initial 


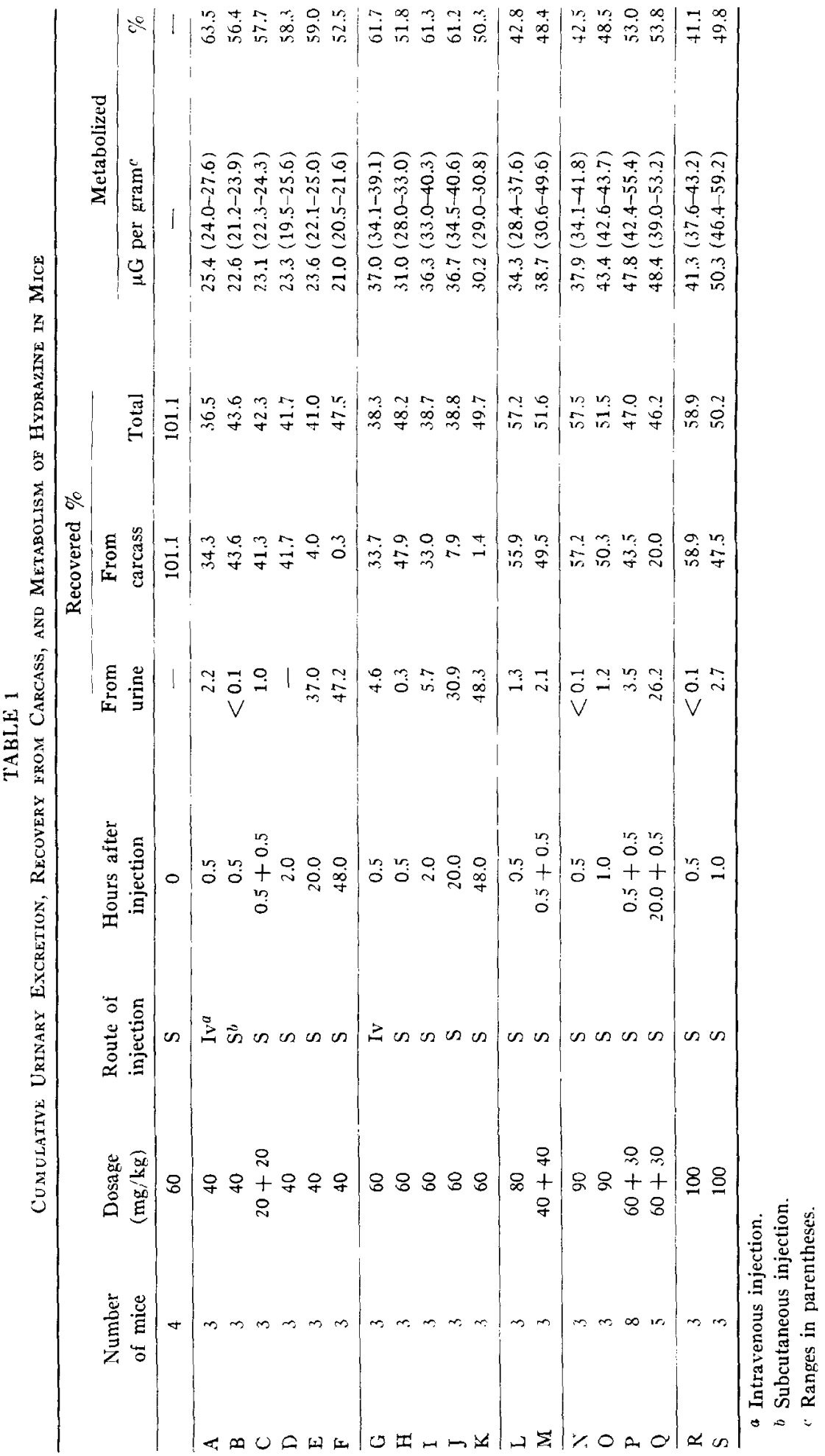


drop in recoverable hydrazine, total hydrazine in urine plus carcass remains relatively constant, most of the carcass hydrazine being excreted in the urine within 24 hours.

\section{The Distribution of Hydrazine in the Rat}

Rats were injected with $60 \mathrm{mg} / \mathrm{kg}$ of hydrazine and sacrificed after 2 and 20 hours. The urine, blood, and whole organs were analyzed for their content of hydrazine (Table 2).

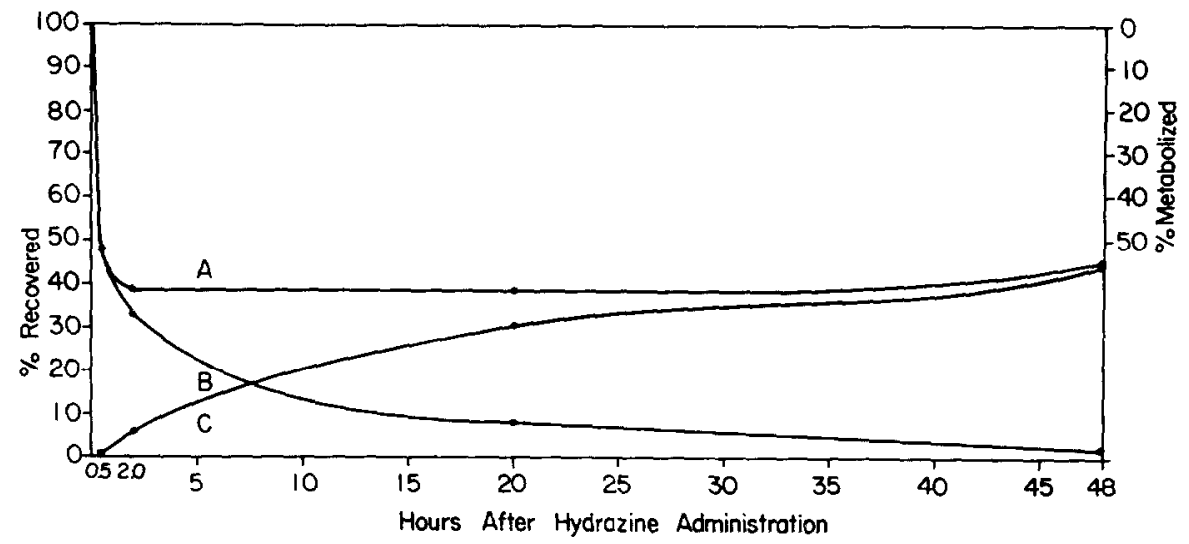

FIG. 3. Fate of hydrazine in mouse after $60 \mathrm{mg} / \mathrm{kg}$ injection. $A$, hydrazine metabolized; $B$, hydrazine recovered from carcass; $C$, hydrazine recovered from urine.

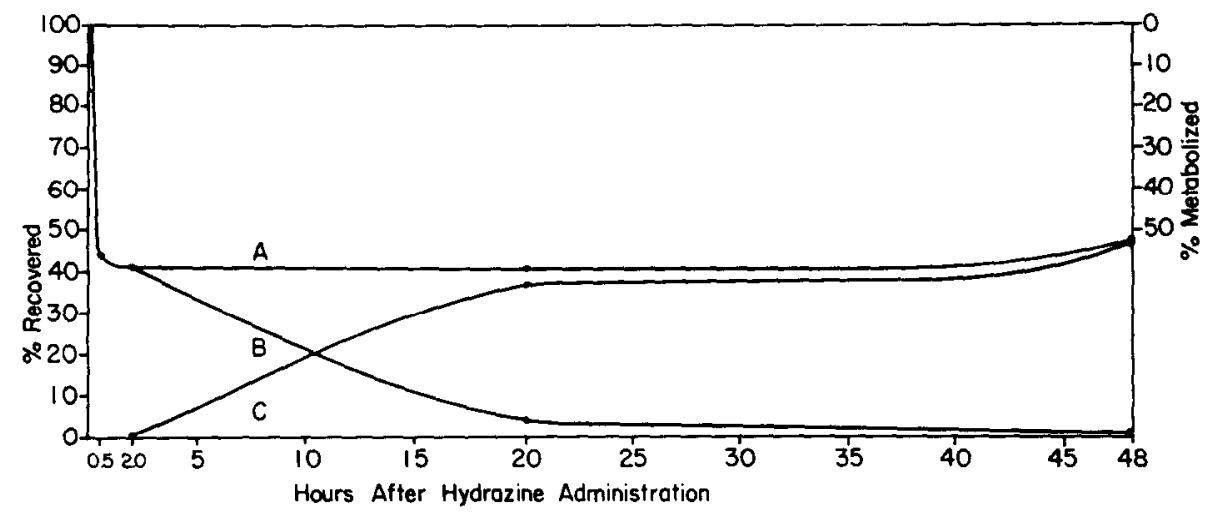

FIG. 4. Fate of hydrazine in mouse after $40 \mathrm{mg} / \mathrm{kg}$ injection. A, hydrazine metabolized; $B$, hydrazine recovered from carcass; $C$, hydrazine recovered from urine.

Samples of skin (most remote part from the injection site), muscle (gluteal), and fat (kidney) were analyzed and the total amount of hydrazine in each organ was estimated and included in Table 2.

The highest concentration of hydrazine was found in the urine. Much higher concentrations were found in the kidney than in any other organ. In the rest of the organs, differences are small. However, 2 hours after injection the general distribution trend can be recognized in the following order of decreasing tissue concentration: spleen, lungs, heart, blood, liver, skin, stomach, intestinal tract, muscle, brain, and fat.

Twenty hours after the administration of hydrazine, the amount excreted in the 


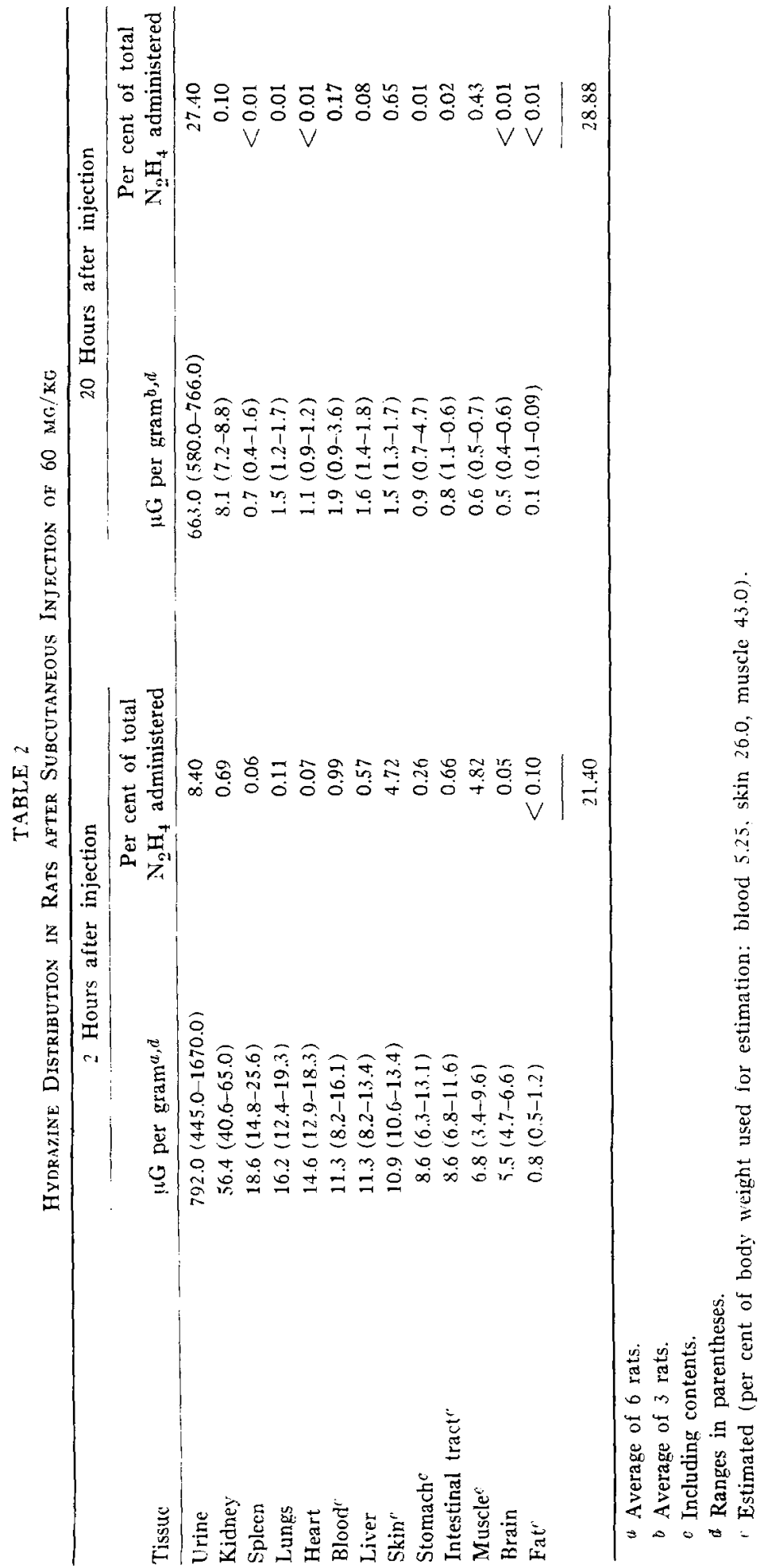


urine had increased considerably and there was a corresponding decrease in the various tissue concentrations (Table 2). It appears that in both the mouse and the rat, a relatively large amount of hydrazine is rapidly metabolized in each animal and the remainder, distributed throughout the various tissues, is excreted in the urine during the subsequent 20-48 hour period (Tables 1 and 2).

Interference by foreign or related compounds with specific analytical methods may raise serious problems in studies of tissue distribution and metabolism. A brief review is presented concerning interferences with the determination of hydrazine by the $p$-dimethylaminobenzaldehyde method.

According to reports concerning the $p$-dimethylaminobenzaldehyde method, ammonium chloride or nitrates (5000:1 mole ratio to hydrazine) do not interfere with hydrazine determination (Watt and Chrisp, 1952). Mono-, di-, and trimethylamines, di- and triethylamines, triethanolamine, glycine, choline, urethan, aminoguanidine, hydroxylamine, phenylhydrazine, chlorides of trimethyl acethydrazide ammonium and acethydrazide-pyridine, and semicarbazide hydrochloride do not interfere with the hydrazine determination (Pesez and Petil, 1947).

It has been reported that 1,2-diacetylhydrazine is excreted (as a detoxication product) in the urine of a rat following the administration of hydrazine (McKennis et al., 1959). Diacetylhydrazine was isolated on paper chromatography by these authors; when sprayed with acid $p$-dimethylaminobenzaldehyde and warmed for 3.5 minutes at $100^{\circ} \mathrm{C}$, it produced orange-yellow spots which are characteristic of the hydrazine determination. During our quantitative (modified colorimetric) and qualitative (Conway diffusion) hydrazine studies, color developed without heating. This would suggest that 1,2-diacetylhydrazine was not measured during the present study of hydrazine distribution in urine and tissues.

Primary aromatic amines, which yield a rose color, urea, adrenalone, and semicarbazide may interfere slightly with the hydrazine determination (Pesez and Petit, 1947; Watt and Chrisp, 1952). It has also been reported that methylhydrazine may interfere with the determination of hydrazine (McKennis et al., 1955). However, bearing in mind that the dilutions in this study were large, it is unlikely that the above-mentioned compounds would have any significant influence on the accuracy of the data presented.

During the investigation of the urinary excretion of hydrazine, $47.2 \%$ of $40-\mathrm{mg} / \mathrm{kg}$ and $48.3 \%$ of the $60-\mathrm{mg} / \mathrm{kg}$ dose was excreted by the mouse in the urine within 48 hours after injection. This is consistent with the report that when the hydrazine nitrogen method was used, dogs excreted approximately $50 \% \mathrm{c}$ of a $15-\mathrm{mg} / \mathrm{kg}$ dose of hydrazine within 2 days after injection (McKennis et al., 1955). Also consistent with their report is the isolation of the $p$-dimethylaminobenzaldazine in this study, suggesting that the excreted hydrazine is free or in some form which readily reacts with p-dimethylaminobenzaldehyde. Hydrazine in the carcass has similarly been identified by the isolation of the specific aldazine. Hydrazine which disappears rapidly within $0.5-2$ hours after injection and is not accounted for in carcass and urine within 2-48 hours, apparently is rapidly metabolized. That metabolic degradation would proceed so rapidly then stop abruptly after approximately half an hour to 2 hours seems unlikely but cannot be ruled out. The complexing of hydrazine, which is a chemically reactive compound, to tissue components could also account 
for the rapid disappearance of a relatively large proportion of the reactive hydrazine. One half hour after the injection of $40 \mu \mathrm{g} / \mathrm{g}, 25 \mu \mathrm{g}$ of hydrazine is "metabolized" whereas at the higher injection levels $60,80,90$, and $100 \mu \mathrm{g} / \mathrm{g}$, the amounts "metabolized" per gram of tissue are $37,34,38$, and $41 \mu \mathrm{g}$, respectively. This would suggest the saturation of binding sites for hydrazine and the relatively rapid excretion of nonbound hydrazine.

Tissue distribution was determined in rats 2 and 20 hours after the subcutaneous injection of hydrazine $(60 \mathrm{mg} / \mathrm{kg})$. Two hours after the injection, approximately $8 \%$ of the dose was excreted in the urine. In the kidney, hydrazine concentration was $56 \mu \mathrm{g} / \mathrm{g}$, which is considerably higher than that found in other tissues. The other tissues varied from 5.5 to $18.6 \mu \mathrm{g} / \mathrm{g}$ with the exception of adipose tissue, which contained only $0.8 \mu \mathrm{g} / \mathrm{g}$. Thus, there appears to be a generalized tissue distribution. The pattern is still the same at 20 hours after injection, kidney containing $8.1 \mu \mathrm{g} / \mathrm{g}$ and all other tissues, excluding fat, ranging from 0.5 to $2.0 \mu \mathrm{g} / \mathrm{g}$. Body fat contained approximately $0.1 \mu \mathrm{g} / \mathrm{g} 20$ hours after injection. At this time, $27.4 \%$ of the dose had becn cxcreted in the urine and only an additional $1.5 \%$ was found in the tissues. Thus, hydrazine shows a general distribution throughout all tissues with the exception of an elevation in kidney and a comparatively low level in fat and brain.

\section{SUMMARY}

Approximately $50 \%$ of 40 - and $60-\mathrm{mg}$ doses of hydrazine per kilogram injected subcutaneously into mice was excreted unchanged in the urine within 48 hours. The present data also suggest that a relatively large amount of hydrazine is rapidly $(0.5-2$ hours) metabolized. Tissue analysis at 2 and 20 hours after the subcutaneous injection of hydrazine in rats indicated a rather uniform distribution throughout most tissues. Kidney concentration was considerably higher than other tissues while fat and brain contained comparatively low levels. Twenty hours after the injection, approximately $27 \%$ of the dose had been excreted in the urine and only $1.5 \%$ remained as free or reactive hydrazine in the tissues.

\section{REFERENCFS}

Dambrauskas, T., and Cornish, H. (1962). A modified spectrophotometric method for the determination of hydrazine. Am. Ind. Hyg. Assoc. J. 23, 151-156.

MCKennis, H., JR. et al. (1955). Studies on the excretion of hydrazine and metabolites. $I$. Pharmacol. Exptl. Therap. 114, 385-1840.

McKennis, H., JR. et al. (1959). Acetylation of hydrazine and the formation of 1,2-diacetylhydrazine in vivo. J. Pharmacol. Exptl. Therap. 126, 109-116.

Prese, M., and Petit, H. (1947). Recherche et dosage de l'hydrazine. Bull. Soc. Chim. France 29, 122-123.

Watt, G. W., and Chrisp, J. D. (1952). A spectrophotometric determination of hydrazine. Anal. Chem. 24, 2006-2008. 